This item was submitted to Loughborough's Research Repository by the author.

Items in Figshare are protected by copyright, with all rights reserved, unless otherwise indicated.

\title{
Online impedance spectroscopy estimation of a dc-dc converter connected battery using an earth leakage monitoring circuit
}

PLEASE CITE THE PUBLISHED VERSION

https://doi.org/10.23919/EPE17ECCEEurope.2017.8098959

\section{PUBLISHER}

IEEE () assigned jointly to the European Power Electronics and Drives Association \& the Institute of Electrical and Electronics Engineers (IEEE)

\section{VERSION}

AM (Accepted Manuscript)

\section{LICENCE}

CC BY-NC-ND 4.0

\section{REPOSITORY RECORD}

Varnosfaderani, Mina Abedi, and Dani Strickland. 2019. "Online Impedance Spectroscopy Estimation of a Dcdc Converter Connected Battery Using an Earth Leakage Monitoring Circuit”. figshare.

https://hdl.handle.net/2134/28160. 


\title{
Online Impedance Spectroscopy Estimation of a dc-dc converter connected Battery using an Earth Leakage Monitoring Circuit
}

\author{
M. A. Varnosfaderani \\ Aston University \\ Engineering and Applied Science Department, Aston \\ University, B4 7ET \\ Birmingham, United Kingdom \\ 01212043737 \\ abedivam@aston.ac.uk
}

\author{
D. Strickland \\ Loughborough University \\ Crest Department \\ Epinal Way, Loughborough LE11 3TU \\ Loughborough, United Kingdom \\ d.strickland@,lboro.ac.uk
}

\section{ACKNOWLEDGMENT}

The authors would like to thank the EPSRC and Opal-RT for their contribution to this project.

\section{KEYWORDS}

$<<$ Batteries $>>,<<$ DC/DC converters $>>,<<$ Frequency Analysis $>>,<<$ Impedance Spectroscopy $>>$

\begin{abstract}
Electrochemical Impedance Spectroscopy (EIS) techniques are useful tools for being able to look at the characterisation of batteries under different conditions and/or with different material components. However, EIS analysis is mostly undertaken offline with bespoke equipment. This paper describes a method of undertaking EIS measurement on-line without the use of additional equipment by manipulating the earth leakage monitoring circuit to generate low frequency excitation signals to analyse a battery system connected to a dc/dc converter. This paper describes the methodology and presents some experimental results compared with off line EIS results generated with more traditional EIS equipment under the same conditions to illustrate the concept.
\end{abstract}

\section{INTRODUCTION}

One of the key issues with an energy storage system is to understand and control the power flow from the system to ensure optimum operation. Battery characterisation parameters such as battery impedance, state of health and state of charge of the battery are a useful representation of the battery conditions. These representations can be used to estimate the battery remaining lifetime, energy storage capacity, and degradation.

Electrochemical impedance spectroscopy (EIS) [1] is a mostly off-line method of data measurement which looks at the electrical characteristics of a material or electrical component such as a battery or solar cells. It is a popular method because of its high level of accuracy and good visualisation through Nyquist diagrams of changes in the system. Additionally, subsequent analysis allows equivalent circuit representations and indications of different chemical processes within the battery. Replicating this technique within an online situation is not without challenges and some attempt has been made within published literature. Within the field of energy storage these can be split into those techniques which use additional hardware to generate a separate excitation circuit [2]-[6] and those that use the main power electronic circuitry [7]-[16] to generate that excitation signal. A separate excitation circuit requires additional hardware in the system which can be expensive. The use of the power electronic circuitry to inject an excitation signal can be divided into two types; techniques which add an additional component of excitation by manipulation of the main switching frequency of the power converters [7][12] and techniques that generate a fundamental signal as the excitation signal from the power converters [12]-[14]. The first method can maintain a high frequency switching operation but at the cost of additional low frequency harmonics in the circuit, while the second method can only excite the circuit at the fundamental frequency which limits the ability of the circuit to undertake a full frequency sweep and generate useful information. It has also been shown that it is possible to generate an excitation signal 
using power electronic controlled inductor based battery balancing hardware [15], [16].

This paper uses a completely different and novel method of injecting a low frequency excitation signal using existing hardware by manipulating the Earth Leakage Monitoring (ELM) hardware that may be present in the system. In the UK, earth leakage monitoring is required on any dc IT system, without an earth connection, with a voltage of over $50 \mathrm{~V}$ [17]. There is a number of commercial earth leakage monitoring relays on the market. These are split between devices which detect and monitor both ac and dc circuits [18], [19] and those that look only at dc systems [20]. An example of the operation for these devices (there are others) is shown in Fig. 1. A low frequency power source applies a signal between the positive and negative terminals of the dc system and ground. This is designed so that negligible current flows through the monitor under normal operation when there is no fault. In the event of an earth fault, an earth leakage current is detected by the instrumentation.

This paper looks at a new method of using an earth leakage monitoring system to inject the low frequency component necessary for on-line EIS measurement of the battery and then sweep this frequency across a range of values to replicate the functionality of the EIS without a need for a separate excitation circuit, while maintaining the earth leakage detection functionality. The battery, in this case, is connected through a dc/dc converter to a load. The battery voltage and current are measured and used to determine the harmonic impedance. The technique is conducted on-line with the battery system operating under normal operation. The changes to the earth leakage monitoring method means that, similar to a separate EIS excitation circuit, the power electronic circuit may see a small harmonic component not present under traditional ELM operation.

The rest of the paper is organised as follows; the next section looks at the development of this technique, the following section presents modeling results of the technique. This is followed by the presentation of experimentally derived results validating the impedance calculated through the online technique with that calculated by Offline EIS measurement.

\section{THEORY}

The key requirement of this method is that it has to generate a low frequency waveform of variable frequency for the EIS calculation while at the same time ensuring normal operation of the power system, in this case, a converter and the earth leakage monitoring system. This work is based on using the hardware available in a standard dc-dc converter topology. The battery is connected to a boost converter (for convenience), while the terminals of the battery are connected to an earth leakage monitor (ELM) to detect any leakage current between the battery terminals and ground. The key to using the ELM hardware is to generate an excitation voltage across the terminal of the battery. Under existing operation there is a high leakage impedance to ground usually in the order of $M \Omega$. The circuit looks like a Wheatstone bridge circuit and under traditional operation if the high impedance resistors are set equal in Fig. 1, the current through the battery would be zero as the leakage impedance from both terminals to ground is sufficiently high to be considered identical. This means that a small current exists in the circuit, but due to the low impedance of the battery $(\mathrm{m} \Omega)$ it is difficult to pick up any current flowing through the battery to analyse.

Fig. 2 shows some ways in which the circuit can be manipulated to increase the flow of earth leakage current through the battery system by deliberately skewing the current in the resistors connected to the positive and negative terminals of the battery. In this paper, the ELM is operated as a connection of two $\mathrm{AC}$ sources connected to the battery terminals through the high impedance resistors connected to a standard dc-dc converter as shown in Fig. 2. This is not unreasonable as most safety relays have two different sources. The frequency of the ELM source is swept over the frequency range for the EIS calculation. The ELM circuit also sees the input impedance of the power converter and load and therefore there may be an additional noticeable ac ripple component present in the power electronics from the ELM. 


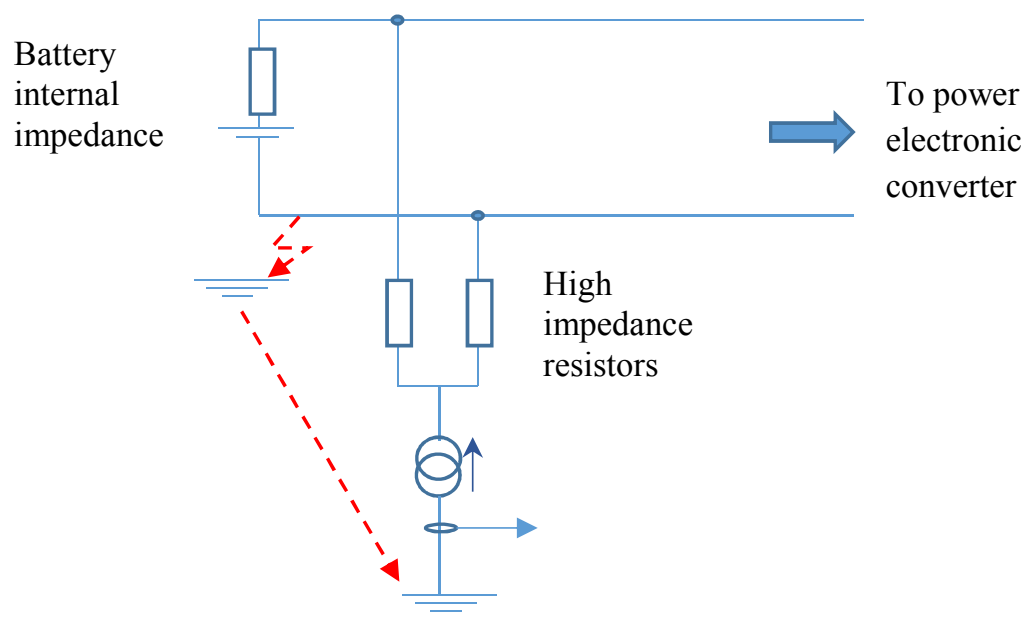

Fig. 1: A representation of earth leakage monitoring circuit operation

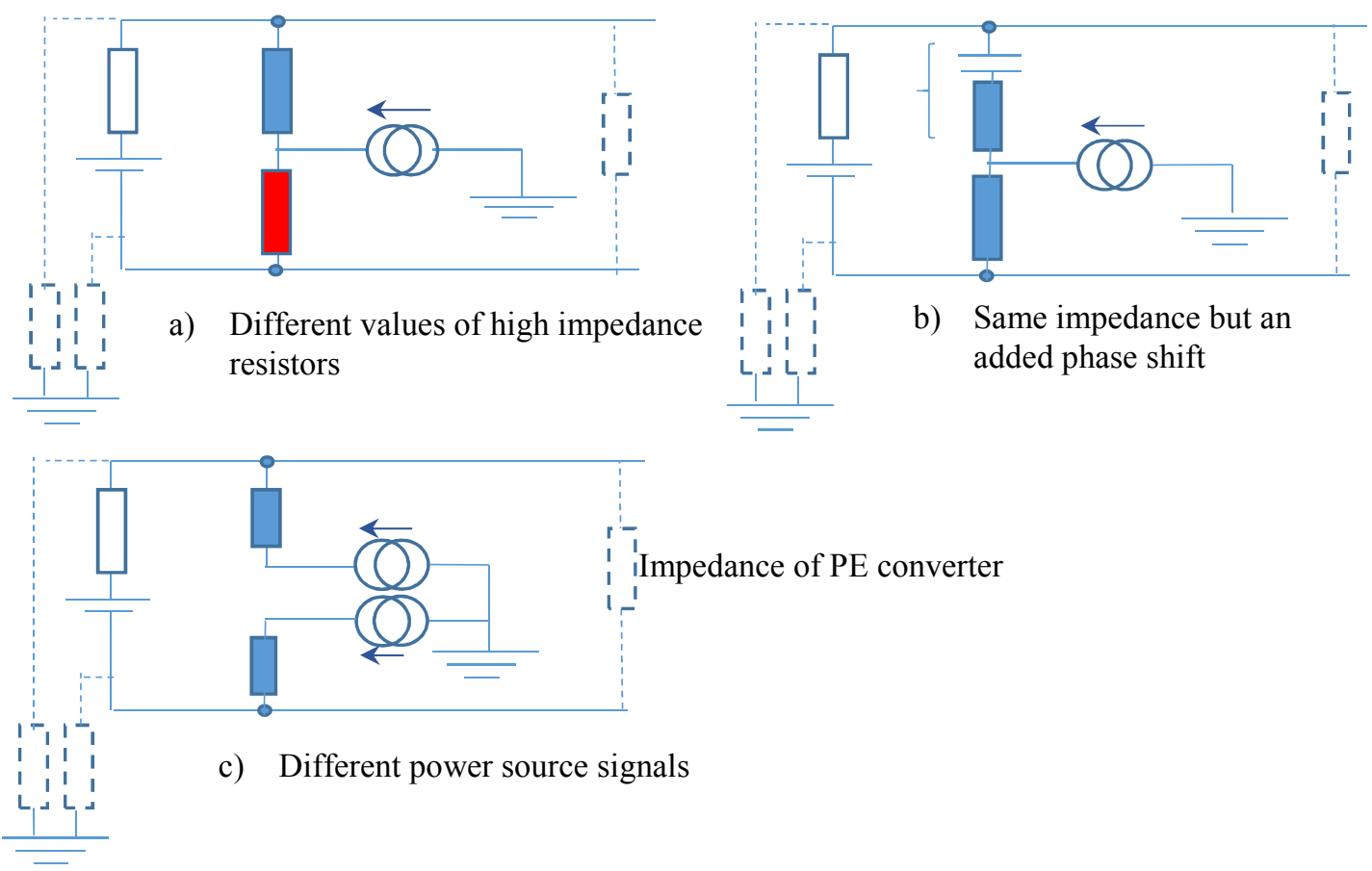

Fig. 2 : Different methods of generating an excitation signal through ELM equipment

The ELM signal adds to the normal circuit operation through super-position to create additional ripple across the battery. To determine what this extra ripple will be - it is necessary to consider the small signal model of the boost converter under open loop control (in this case with ideal components). When the switch is on:

$$
\begin{aligned}
& V_{b a t}=L \frac{d I_{b a t}}{d t} \\
& \frac{V_{d c}}{R_{L}}=-C \frac{d V_{c}}{d t}
\end{aligned}
$$

When the switch is off:

$$
\begin{aligned}
& V_{b a t}=L \frac{d I_{b a t}}{d t}+V_{d c} \\
& \frac{V_{d c}}{R_{L}}=I_{b a t}-C \frac{d V_{d c}}{d t}
\end{aligned}
$$


Where $V_{b a t}$ and $I_{b a t}$ are battery voltage and current, $V_{d c}$ is the converter output voltage, L, C and $R_{L}$ are converter inductor, capacitor and load resistor. For a small signal model, averaging, perturbation and linear approximation are used. The averaged equations are:

$$
\begin{aligned}
& \bar{V}_{b a t}=L \frac{d\left(\bar{I}_{b a t}\right)}{d t}+(1-\bar{d}) \bar{V}_{d c} \\
& \frac{\bar{V}_{d c}}{R_{L}}=(1-\bar{d}) \bar{I}_{b a t}-C \frac{d \bar{V}_{d c}}{d t}
\end{aligned}
$$

In this work the duty cycle, $\mathrm{d}$, is fixed, but the voltage $V_{b a t}$ can be considered subject to a small perturbation caused by the ELM low frequency injection.

$$
\begin{aligned}
& \bar{V}_{b a t}+\tilde{v}_{E L M}=L \frac{d\left(\bar{I}_{b a t}+\tilde{\imath}_{E L M}\right)}{d t}+(1-\mathrm{d})\left(\bar{V}_{d c}+\widetilde{v}_{d c}\right) \\
& \frac{\bar{V}_{d c}+\widetilde{v}_{d c}}{R_{L}}=(1-d)\left(\bar{I}_{b a t}+\tilde{\imath}_{E L M}\right)-C \frac{d\left(\bar{V}_{d c}+\widetilde{v}_{d c}\right)}{d t}
\end{aligned}
$$

Where $\tilde{v}_{E L M}$ and $\tilde{\imath}_{E L M}$ are the earth leakage voltage and current as seen by the battery. Using linearisation, a set of DC equations can be obtained as follows:

$$
\begin{aligned}
& \bar{V}_{b a t}=(1-\mathrm{d}) \bar{V}_{d c} \\
& \frac{\bar{V}_{d c}}{R_{L}}=(1-d) \bar{I}_{b a t}
\end{aligned}
$$

Giving a DC input impedance to the power electronic converter of:

$$
\bar{Z}_{P E}=\frac{\bar{V}_{b a t}}{\bar{I}_{\text {bat }}}=(1-\mathrm{d})^{2} \mathrm{R}_{L}
$$

From the parameters in Table I. This approximates to:

$$
\bar{Z}_{P E}=16(1-0.6)^{2} \approx 2.56 \Omega \gg Z_{B A T}
$$

A similar set of equations for the AC signal can be obtained:

$$
\begin{aligned}
& \tilde{v}_{E L M}=s L \tilde{\imath}_{E L M}+(1-\mathrm{d}) \widetilde{v}_{d c} \\
& \frac{\widetilde{v}_{d c}}{R_{L}}=(1-d) \tilde{\imath}_{E L M}-s C \widetilde{v}_{d c}
\end{aligned}
$$

Substituting gives

$$
\begin{aligned}
& \frac{\frac{\tilde{v}_{E L M}-s L \tilde{E}_{E L M}}{(1-\mathrm{d})}}{R_{L}}=(1-d) \tilde{l}_{E L M}-s C \frac{\tilde{v}_{E L M}-s L \tilde{i}_{E L M}}{(1-\mathrm{d})} \\
& \tilde{z}_{P E}=\frac{\tilde{v}_{E L M}}{\tilde{\imath}_{E L M}}=\frac{R_{L}(1-d)^{2}+s L+s^{2} C R_{L} L}{\left(1+s C R_{L}\right)}
\end{aligned}
$$

At a value of $125 \mathrm{~Hz}$ using the parameters from Table I gives an impedance of $315 \mathrm{~m} \Omega$ which is again greater than the battery impedance. The high impedance resistance is set to $10 \Omega$ and the two sources have the same magnitude but a phase shift of $45^{\circ}$.

The earth leakage current in the event of a fault would register a current of approx. 2A rms:

$$
\begin{aligned}
& I_{E L M} \approx 1.2\left(\sin (\omega t)+\sin \left(\omega t+\frac{\pi}{4}\right)\right) \\
& I_{E L M} \approx 2.21\left(\sin \left(\omega t+\frac{\pi}{8}\right)\right)
\end{aligned}
$$

While the voltage across the battery under normal operation can be calculated to be approximately:

$$
\begin{aligned}
& V_{\text {batt }, a c} \approx \frac{Z_{\text {batt }}}{Z_{\text {batt }}+20} 12\left(\sin (\omega t)-\sin \left(\omega t+\frac{\pi}{4}\right)\right) \\
& V_{\text {bat }, a c} \approx \frac{Z_{\text {batt }}}{Z_{\text {batt }}+20} 9.2\left(\sin \left(\omega t+\frac{\pi}{8}\right)\right)
\end{aligned}
$$


This gives a peak of approximately $5 \mathrm{mV}$ which is small but detectable through the scope probes an in keeping with the magnitude of the off-line EIS equipment and similar values published in literature [21]-[24]. Within this circuit, it is therefore possible to detect both an earth leakage current and a small EIS signal.

The increase in battery ripple current is the result of the super-position of the ELM produced current in conjunction with the normal ripple current from the boost converter operation. This can be seen in Fig. 3 which shows the ripple current through the battery (blue) is equal to the super-position of the battery current with no ELM (orange) and the small signal battery current which is a function of the ELM (grey).

The increase in current compared to the scenario with no ELM is therefore:

$$
\text { ripple increase }=1+\frac{\tilde{b}_{b a t, a c}}{I_{\text {bat }}}=1+\frac{\frac{9.2}{Z_{b a t}+20}}{\frac{1}{L} d T_{s} V_{b a t}}=1+\frac{9.2 L}{\left(Z_{b a t t}+20\right) d T_{S} V_{b a t}}
$$

The ripple increase is a function of the impedance of the battery. As the battery degrades, its impedance increases resulting in a less accurate calculation.

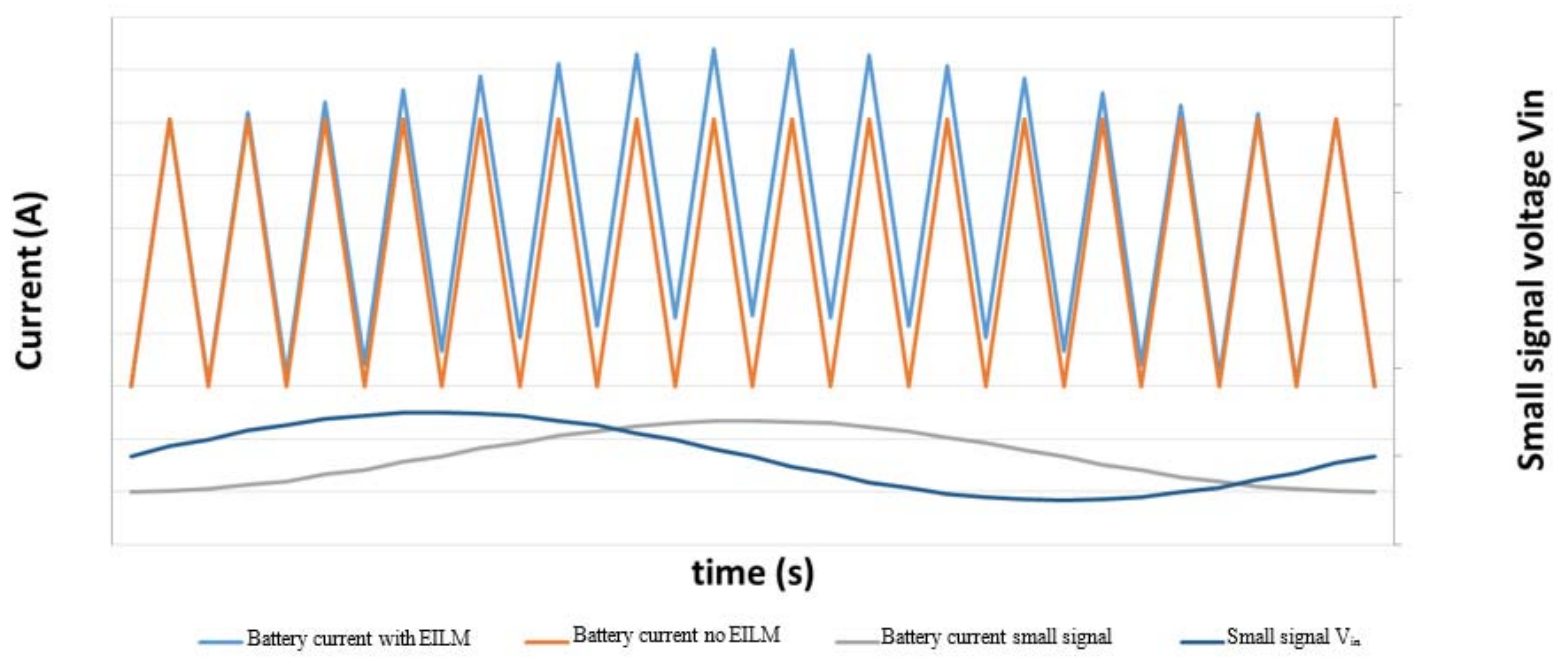

Fig. 3 : Ripple current through the battery

Fourier analysis can also be used to study the current waveform seen by the battery. In steady state condition the inductor current over one switching cycle in boost mode in an ideal converter can be calculated as:

$$
\begin{aligned}
& \Delta i_{o n}=\frac{1}{L}\left(V_{b a t}+\tilde{v}_{E L M}\right) d T_{S} \\
& \Delta i_{o f f}=\frac{1}{L}\left(V_{b a t}+\tilde{v}_{E L M}-V_{d c}\right)\left(T_{S}-d T_{S}\right) \\
& \Delta i_{o n}+\Delta i_{o f f}=\frac{1}{L}\left(V_{b a t}+\tilde{v}_{E L M}\right) d T_{S}+\frac{1}{L}\left(V_{b a t}+\tilde{v}_{E L M}-V_{d c}\right)\left(T_{S}-d T_{S}\right)
\end{aligned}
$$

Simplification gives:

$$
\Delta i_{\text {on }}+\Delta i_{\text {off }}=\frac{1}{L} V_{b a t} d T_{S}+\frac{1}{L}\left(V_{b a t}-V_{d c}\right)\left(T_{S}-d T_{S}\right)+\frac{1}{L} \tilde{v}_{E L M} T_{S}
$$

By substituting (18) in (25):

$$
\Delta i_{\text {on }}+\Delta i_{\text {off }}=\frac{1}{L} V_{\text {bat }} d T_{S}+\frac{1}{L}\left(V_{\text {bat }}-V_{d c}\right)\left(T_{S}-d T_{S}\right)+\frac{1}{L} \frac{Z_{\text {batt }}}{Z_{\text {batt }}+20} 9.2\left(\sin \left(\omega t+\frac{\pi}{8}\right)\right) T_{S}
$$

Fourier analysis of this current can then be undertaken. 


\section{Modelling}

To help validate the methodology, it is useful to simulate the circuit and compare the output waveforms with those generated theoretically and experimentally. To undertake a circuit simulation, the impedance of a battery, an A123 Lithium-ion phosphate with 2.5 Ah capacity, for use in the model was found by EIS measurement and represented in a MATLAB simulation as an equivalent circuit as shown in Fig. 4.

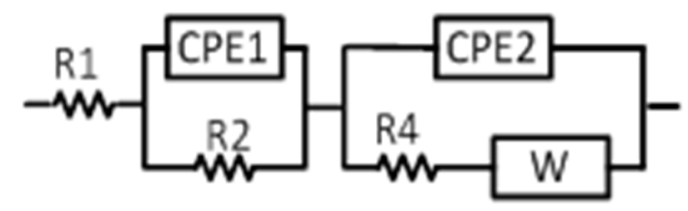

Fig. 4 : Equivalent circuit model of the Li-Ion battery

The battery component values were estimated from the off-line EIS measurement of the battery under $100 \%$ state of charge at room temperature. The boost converter was designed such that it operated in continuous conduction mode at a switching frequency of $2 \mathrm{kHz}$ with a duty cycle of 0.6 for a battery voltage of $3.21 \mathrm{~V}$. Table I represents the estimated battery equivalent circuit parameters and boost converter components. The ELM hardware was fixed so that the two sources were used to produce a value of $12 \mathrm{~V}$ with a phase difference of $45^{\circ}$, while the high impedance resistors were set to $10 \Omega$.

Table I : Battery parameters estimated from offline EIS and converter details

\begin{tabular}{|c|l||l|l|}
\hline Battery Parameters & Values & $\begin{array}{l}\text { Boost converter } \\
\text { Components }\end{array}$ & Specifications \\
\hline$R_{1}(\Omega)$ & 0.0069 & Inductance & $380 \mu \mathrm{H}, 20$ A ,Toroidal \\
\hline$R_{2}(\Omega)$ & 0.0056 & Capacitance & $13600 \mu \mathrm{F}, 16 \mathrm{~V}$ Electrolytic \\
\hline$R_{4}(\Omega)$ & 0.00089 & Load & $16 \Omega$ resistor \\
\hline$C P E_{1}$ & 3.36 & Switch MOSFET & FDPF045N10A, 100 V, 67 A, 4.5 m $\Omega$ \\
\hline$C P E_{2}$ & 0.43 & Diode & HER204G Rectifier Diode (max 2A) \\
\hline
\end{tabular}

\section{EXPERIMENTAL RESULTS}

The experimental setup used to look at on-line low frequency impedance measurement as described above is shown in Fig. 5. The impedance at different frequencies was calculated by measuring the battery voltage and current using a Lecroy $100 \mathrm{MHz}$ current probe and a Tektronix P2220 $200 \mathrm{MHz}$ voltage probe for convenience, but an ACS712 current sensor and IL300 voltage sensor measurement device linked to the controller have also been used to get the same results.

Fig. 6 shows the experimentally captured battery current and voltage both without the ELM and with the ELM operating at a low frequency of $125 \mathrm{~Hz}$. The injected low-frequency using the ELM creates added ripple to the battery current which is clearly visible. The resulting waveform is the result of the superposition of the boost converter and the ELM current signals. A comparison of the experimental and simulation key parameters are shown in Table II. The experimental values of the load output voltage and ripple and the load current and ripple are lower than the simulation values. This is because of the non-ideal and non-linear components present in the experimental setup that aren't included in the modelling including, diode, mosfet, and ESR resistances. In both the experimental setup and the simulation model, the boost ratio, load current and voltage remain the same as the circuit with no ELM hardware. Fig. 7 shows the harmonic analysis of the experimentally measured and theoretically calculated battery current from (26) using the ELM method. Both low frequency and switching frequency harmonics are observed in the harmonic spectrum of the current. 


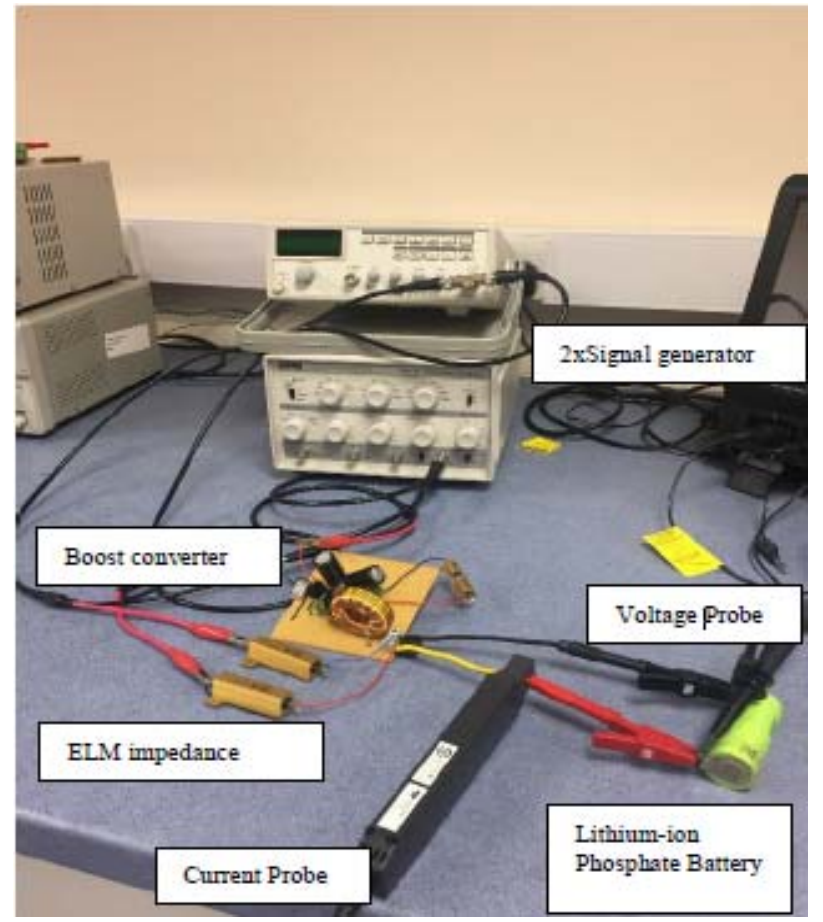

Fig. 5 : Experimental set up

(a)
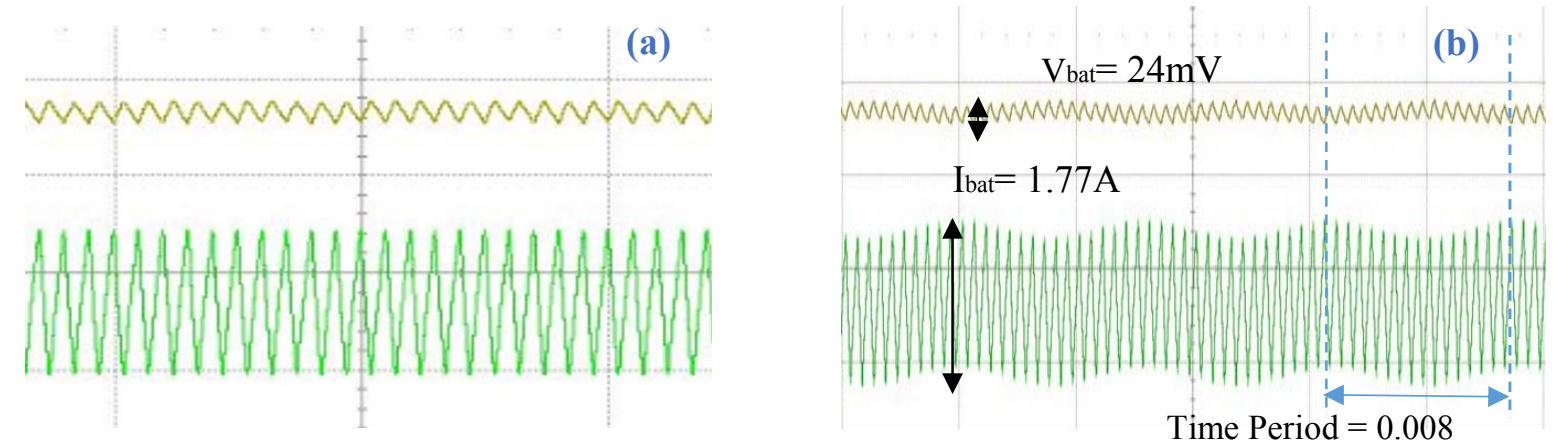

Fig. 6 : Li-ion battery current (green) and voltage (yellow) waveforms, when the battery is operating with PWM at a fixed duty cycle and (a) no ELM (b) the ELM is operating at $125 \mathrm{~Hz}$.

Table II: Comparison of the base circuit data with the ELM circuit at $125 \mathrm{~Hz}$

\begin{tabular}{|c|c|c|c|c|}
\hline & \multicolumn{4}{|c|}{ Experimental } \\
\hline & \multicolumn{2}{|c|}{ Fixed Duty Cycle } & \multicolumn{2}{|c|}{ Earth Leakage connected to the converter } \\
\hline & Average Value & Peak-Peak ripple & Average Value & Peak-Peak ripple \\
\hline$I_{b a t}$ & $1.18 \mathrm{~A}$ & $1.49 \mathrm{~A}$ & $1.25 \mathrm{~A}$ & $1.77 \mathrm{~A}$ \\
\hline$V_{\text {bat }}$ & $3.21 \mathrm{~V}$ & $12.5 \mathrm{mV}$ & $3.2 \mathrm{~V}$ & $24 \mathrm{mV}$ \\
\hline$I_{\text {load }}$ & $420 \mathrm{~mA}$ & $10 \mathrm{~mA}$ & $420 \mathrm{~mA}$ & $10 \mathrm{~mA}$ \\
\hline \multirow[t]{4}{*}{$V_{d c}$} & $6.89 \mathrm{~V}$ & $67 \mathrm{mV}$ & $6.88 \mathrm{~V}$ & $67 \mathrm{mV}$ \\
\hline & \multicolumn{4}{|c|}{ Simulation } \\
\hline & \multicolumn{2}{|c|}{ Fixed Duty Cycle } & \multicolumn{2}{|c|}{ Earth Leakage connected to the converter } \\
\hline & Average Value & Peak-Peak ripple & Average Value & Peak-Peak ripple \\
\hline$I_{\text {bat }}$ & $1.55 \mathrm{~A}$ & $2.42 \mathrm{~A}$ & $1.7 \mathrm{~A}$ & $3.32 \mathrm{~A}$ \\
\hline$V_{\text {bat }}$ & $3.21 \mathrm{~V}$ & $16.8 \mathrm{mV}$ & $3.2 \mathrm{~V}$ & $24 \mathrm{mV}$ \\
\hline$I_{\text {load }}$ & $456 \mathrm{~mA}$ & $0.7 \mathrm{~mA}$ & $455 \mathrm{~mA}$ & $0.7 \mathrm{~mA}$ \\
\hline$V_{d c}$ & $7.3 \mathrm{~V}$ & $11.1 \mathrm{mV}$ & $7.3 \mathrm{~V}$ & $11.8 \mathrm{mV}$ \\
\hline
\end{tabular}


The experimental increase in battery ripple current is $19 \%$ compared to a theoretical increase of $18 \%$ from (21).
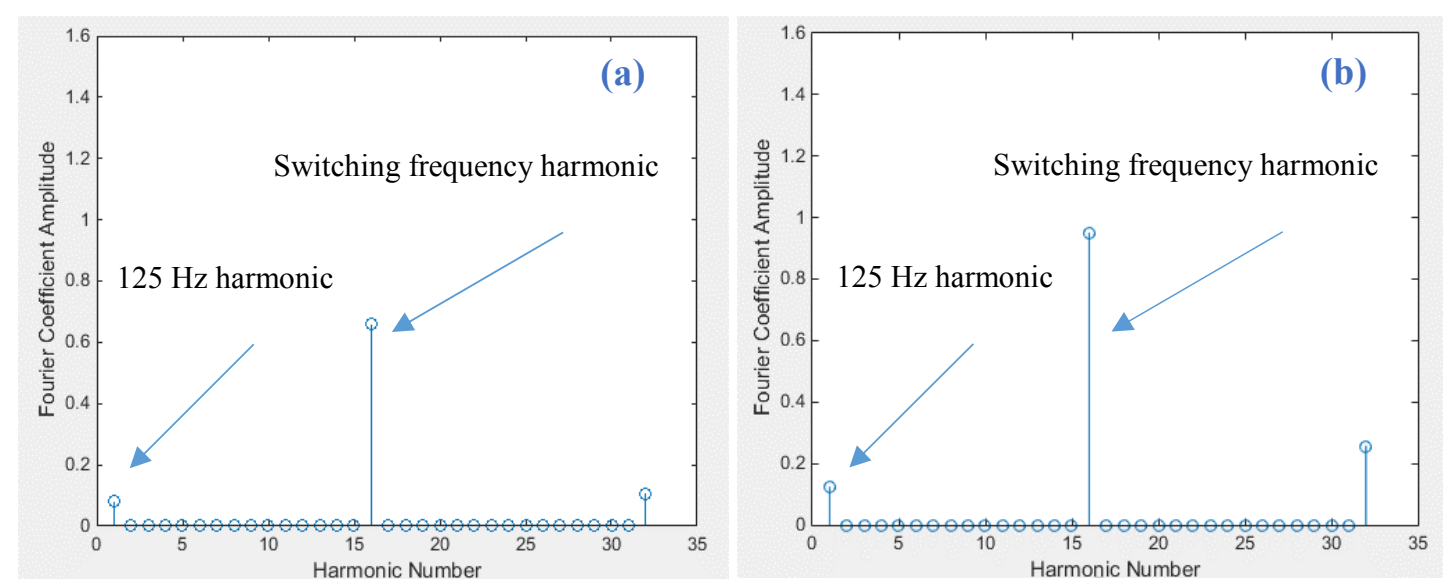

Fig. 7 : (a) Experimentally (b) Theoretically derived harmonics of the Li-ion battery current signal with an ELM signal at a low frequency of $125 \mathrm{~Hz}$

From the recorded values of battery current and voltage the low frequency component is extracted and the voltage divided by the current to give the complex impedance at that frequency. To verify the proposed method is suitable for on-line EIS applications, the calculated battery impedance data from experimental and simulation were compared with offline measured EIS data. This is shown in Fig. 8, as impedance data presented in three typical impedance formats; amplitude, phase, and complex plots. The measured complex impedance of the Li-ion battery from off line EIS measurement equipment (in red), experimental test (in blue dots), and simulation (in black) is shown. Results are similar from all three sources.

\section{CONCLUSION}

This paper presents an analysis of a method to extract the harmonic impedance of a battery under normal operation by injecting a low frequency excitation signal using earth leakage monitoring hardware. The impact of the magnitude of that variation on the battery ripple current has been shown and simulated. This excitation can be used to look at the harmonic impedance of the battery under operation. The methodology has been experimentally validated and a Nyquist plot of a battery produced using this methodology compared to an off-line EIS measurement has been produced while the battery was operating in boost mode. There is still much work to be done in this area including modifying the modeling to include non-ideal components, determining the impact on discontinuous boost operation and closed loop control. However, this paper provides valuable insights into the trade-off in ripple current with convenient impedance measurement and suggests that this may be a valid method for monitoring online impedance. 

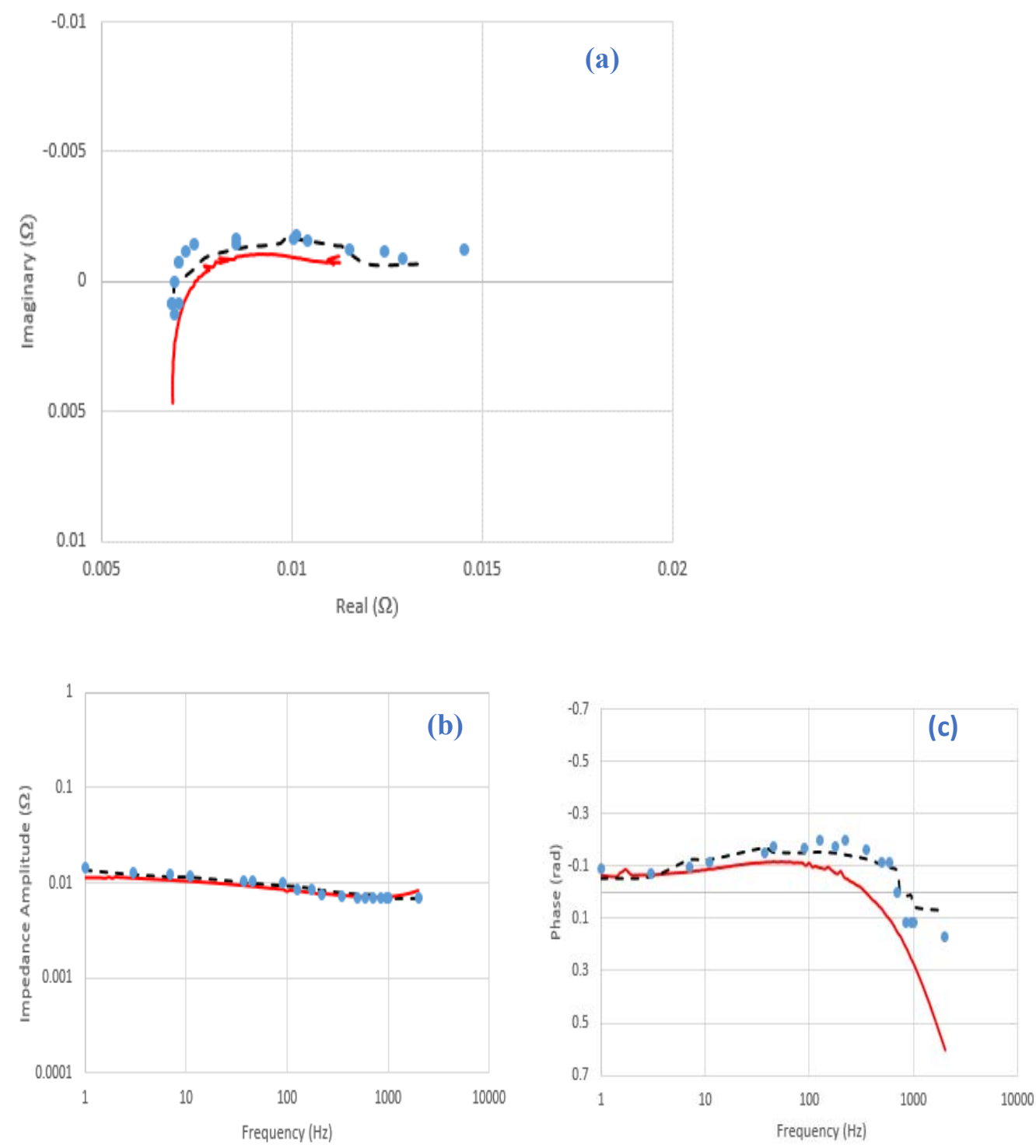

Fig. 8: (a) Impedance Nyquist plot (b) Impedance amplitude bode plot (c) Impedance phase bode plot of the Li-ion battery with EIS (red), Simulation (black), and Experimental results (blue dots)

\section{REFERENCES}

[1] E. Barsoukov and J. R. Macdonald, Impedance spectroscopy: theory, experiment, and applications, 2nd ed. /. Hoboken, N.J. [Chichester], Wiley-Interscience, 2005.

[2] R. Koch, R. Kuhn, I. Zilberman, and A. Jossen, "Electrochemical impedance spectroscopy for online battery monitoring - power electronics control," in Power Electronics and Applications (EPE'14-ECCE Europe), 2014 16th European Conference on, 2014, pp. 1-10.

[3] L. Zhao, Q. Fu, and Z. Liu, "An electrochemical impedance spectroscopy measurement system for electric vehicle batteries," in 2016 35th Chinese Control Conference (CCC), 2016, pp. 5050-5055.

[4] X. Wang, X. Wei, H. Dai, and Q. Wu, "State Estimation of Lithium Ion Battery Based on Electrochemical Impedance Spectroscopy with On-Board Impedance Measurement System," in 2015 IEEE Vehicle Power and Propulsion Conference (VPPC), 2015, pp. 1-5.

[5] S.-Y. Cho, I.-O. Lee, J.-I. Baek, and G.-W. Moon, "Battery Impedance Analysis Considering DC Component in Sinusoidal Ripple-Current Charging," IEEE Trans. Ind. Electron., vol. 63, no. 3, pp. 15611573, Mar. 2016.

[6] U. Tröltzsch and O. Kanoun, "Miniaturized Impedance Measurement System for Battery Diagnosis," in 
Proceedings SENSOR 2009, Volume I, 2009, pp. 251-256.

[7] W. Huang and J. A. Qahouq, “An Online Battery Impedance Measurement Method Using DC-DC Power Converter Control,” Ind. Electron. IEEE Trans., vol. 61, no. 11, pp. 5987-5995, 2014.

[8] M. A. Varnosfaderani and D. Strickland, "Online impedance spectroscopy estimation of a battery," in 2016 18th European Conference on Power Electronics and Applications (EPE'16 ECCE Europe), 2016, pp. $1-10$.

[9] N. Katayama and S. Kogoshi, "Real-Time Electrochemical Impedance Diagnosis for Fuel Cells Using a DC-DC Converter,” IEEE Trans. Energy Convers., vol. 30, no. 2, pp. 707-713, Jun. 2015.

[10] J. A. A. Qahouq, "Online Battery Impedance Spectrum Measurement Method," in 2016 IEEE Applied Power Electronics Conference and Exposition (APEC), 2016, pp. 3611-3615.

[11] D. Depernet, O. Ba, and A. Berthon, "Online impedance spectroscopy of lead acid batteries for storage management of a standalone power plant," J. Power Sources, vol. 219, pp. 65-74, 2012.

[12] R. Koch, C. Riebel, and A. Jossen, "On-line electrochemical impedance spectroscopy implementation for telecommunication power supplies" in 2015 IEEE International Telecommunications Energy Conference (INTELEC), 2015, pp. 1-6.

[13] D. A. Howey, P. D. Mitcheson, V. Yufit, G. J. Offer, and N. P. Brandon, "Online Measurement of Battery Impedance Using Motor Controller Excitation,” Veh. Technol. IEEE Trans., vol. 63, no. 6, pp. 2557-2566, 2014.

[14] R. Koch, R. Kuhn, I. Zilberman, and A. Jossen, "Electrochemical impedance spectroscopy for online battery monitoring - power electronics control," in 2014 16th European Conference on Power Electronics and Applications, 2014, pp. 1-10.

[15] E. Din, C. Schaef, K. Moffat, and J. T. Stauth, "Online spectroscopic diagnostics implemented in an efficient battery management system," in 2015 IEEE 16th Workshop on Control and Modeling for Power Electronics, COMPEL 2015, 2015.

[16] E. Din, C. Schaef, K. Moffat, and J. Stauth, "A Scalable Active Battery Management System with Embedded Real-Time Electrochemical Impedance Spectroscopy," IEEE Trans. Power Electron., vol. PP, no. 99, 2016.

[17] British. Standard. BS. 7671., Requirements for Electrical Installations. IET Wiring Regulations, 17 th ed. 2008.

[18] "Eaton EMR4-R Earth Leakage Monitor." [Online]. Available: http://www.moeller.net/en/products_solutions/motor_applications/control/measuring_relay/earth_leakag e_monitor.jsp. [Accessed $16^{\text {th }}$ May 2016 ]

[19] "Bender Earth leakage monitoring." [Online]. Available: http://www.bender.org/products/iso685/. [Accessed 16 ${ }^{\text {th }}$ May 2016]

[20] “Thiim earth leakage monitor." [Online]. Available: http://thiim.com/datasheets/ddea.pdf [Accessed $16^{\text {th }}$ May 2016].

[21] J. Vetter et al., "Ageing mechanisms in lithium-ion batteries," J. Power Sources, vol. 147, no. 1-2, pp. 269-281, 2005.

[22] J. Shim, R. Kostecki, T. Richardson, X. Song, and K. A. Striebel, "Electrochemical analysis for cycle performance and capacity fading of a lithium-ion battery cycled at elevated temperature.",Elsevier, Science direct, pp222 - 230, 2002.

[23] M. Mirzaeian and P. J. Hall, "Characterizing capacity loss of lithium oxygen batteries by impedance spectroscopy,” J. Power Sources, vol. 195, no. 19, pp. 6817-6824, 2010.

[24] D. Andre, C. Appel, T. Soczka-Guth, and D. U. Sauer, "Advanced mathematical methods of SOC and SOH estimation for lithium-ion batteries," J. Power Sources, vol. 224, no. 0, pp. 20-27, 2013. 